\title{
Keratoconjunctivitis and Periorbital Edema due to Ecballium elaterium
}

\author{
Dimitrios Brouzas Mariana Oanta Eleni Loukianou \\ Marillita Moschos
}

1st Department of Ophthalmology, University of Athens Medical School, Athens, Greece

\section{Key Words}

Ecballium elaterium · Squirting cucumber · Keratoconjunctivitis · Periorbital edema

\begin{abstract}
Purpose: To report on a case of keratoconjunctivitis with periorbital edema after accidental exposure to undiluted juice of Ecballium elaterium fruit during the ripening season of this plant.

Methods: Case report.

Results: Keratoconjunctivitis with Descemet's membrane folds and superficial upper corneal well-defined edematous areas were noted after an Ecballium elaterium fruit burst and its juice splashed into the patient's left eye. Prompt administration of antibiotic and steroid eye drops along with per os antihistamine therapy, resulted in quick regression of symptoms. Conclusions: This report demonstrates the toxic effects of this herb to the eye and also that prompt therapy is effective.
\end{abstract}

Ecballium elaterium ('squirting cucumber') is a plant belonging to the Cucurbitaceae family. It is a decumbent perennial herb indigenous to the Mediterranean region and cultivated in central Europe and England. The fruit is ovoid, fleshy, approximately 3$4 \mathrm{~cm}$ in length, when unripe of a pale green color and covered with numerous hairs (fig, 1).

The name 'squirting cucumber' comes from the property of the ripe fruit to explode upon the slightest touch. As it ripens, the fruit fills with a slimy juice. Eventually, the pressure within becomes so great that the cucumber bursts off its stalk and shoots through the air at a distance of several meters. Behind it, streaming from the hole in its base, like gases flaring behind a space rocket, comes a trail of slime and with it dark seeds. Its roots and fruit have been used in folk medicine since antiquity [1]. The diluted aqueous extract from the fruit of the squirting cucumber is a traditional antiinflammatory and analgesic remedy for chronic sinusitis by nasal aspiration [2]. The 
use of squirting cucumber juice for the treatment of chronic sinusitis dates back to Dioscurides (20-79 AD). Other traditional uses include the treatment of fever, cancer, liver cirrhosis, constipation, hypertension and rheumatic disease [3]. This plant, and especially its fruit, has also been used as an abortifacient in the ancient world.

\section{Case Report}

A 70-year-old male farmer presented to the emergency department with periorbital pain, periorbital and conjunctival edema, epiphora, hyperemia, irritation, and blurred vision from his left eye after inadvertent exposure to undiluted juice of Ecballium elaterium fruit some hours earlier. The symptoms began within minutes after the herb's fruit bursted and juice splashed into the eye (fig. 2 ).

The examination revealed periorbital edema and extensive conjunctival chemosis. Slit lamp examination revealed corneal epithelial micro-erosions, corneal superficial well-defined edematous areas mainly in the peripheral upper quadrants ( $\mathrm{fig} .3 \mathrm{a}$ ), Descemet's membrane folds (fig. 3b) and moderate anterior chamber flare. The IOP was normal as well as the fundus examination.

The patient was treated promptly with eye irrigation, topical steroids for periorbital edema, combination of antibiotic and steroid eye drops along with antihistamine tablets. Within four days from the initiation of treatment, the symptoms subsided and the patient was discharged from the hospital.

\section{Discussion}

Exposure to Ecballium elaterium fruit juice, mainly in its undiluted form, may cause irritation of the mucous membrane. All parts of this plant are toxic. The toxicity is attributed to alkaloids named cucurbitacins or elaterins. Elaterium is the dried sediment that deposits in the juice of the fruits of Ecballium elaterium. It is a powerful cathartic and contains up to $30 \%$ of elaterin, which is the active ingredient. The use of elaterin is frequently followed by prostration. According to Sollmann [4], the toxic dose is $5 \mathrm{mg}$ and the fatal dose $0.6 \mathrm{~g}$.

Published adverse reactions related to the toxic effect of this remedy include localized swelling of the uvula [5], the nasal mucosa and others sites of the upper respiratory tract of allergy-prone patients [6]. Also, there is a report of fatal cardiac and renal failure probably related to Ecballium elaterium juice intake [7]. Regarding the eye, Kocak et al. [8] reported a case of late-onset diffuse lamellar keratitis 11 months after LASIK, when an Ecballium elaterium herb fruit burst and splashed into the patient's eye. Topical steroid treatment was administered and keratitis healed within 2 weeks without complications. Also, Raikhlin-Eisenkraft and Bentur [1] report 6 cases with ocular exposure presented with conjunctivitis, corneal edema, and erosion. All patients responded to topical steroid and antibiotic eye drops within a few days.

\section{Conclusion}

This report demonstrates the toxic effect of Ecballium elaterium juice to the eye and also, that prompt therapy results in rapid regression of symptoms. 


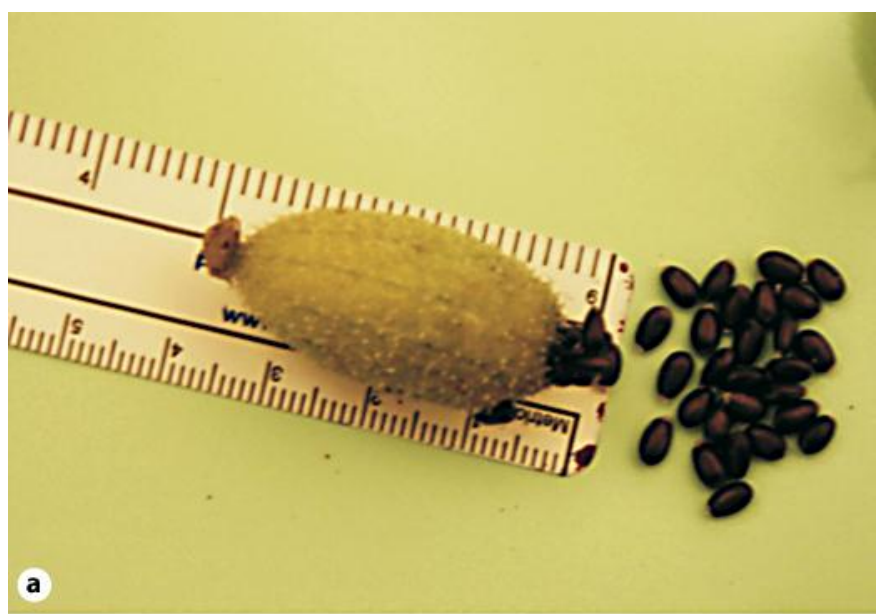

a

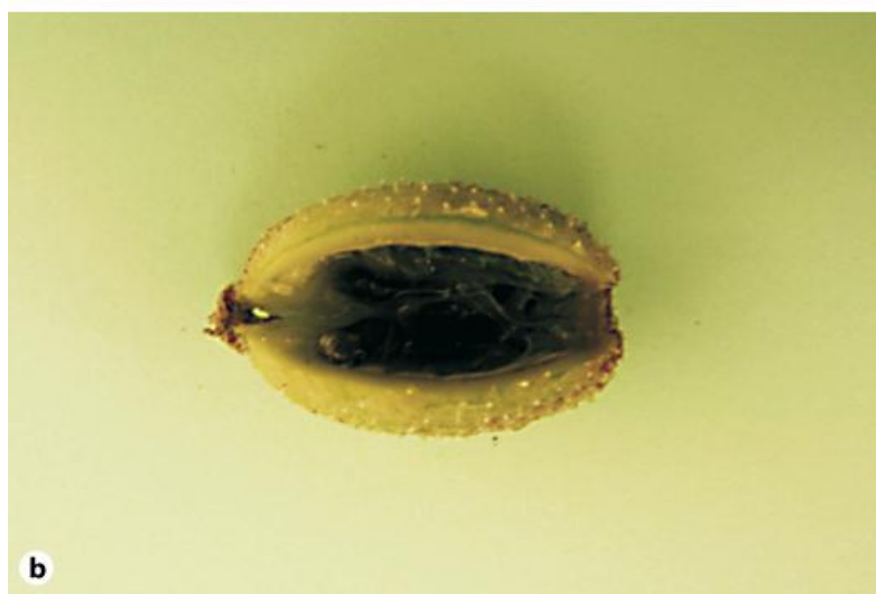

Fig. 1. Ecballium elaterium. a Fruit with its seeds. b Dissection of the fruit.
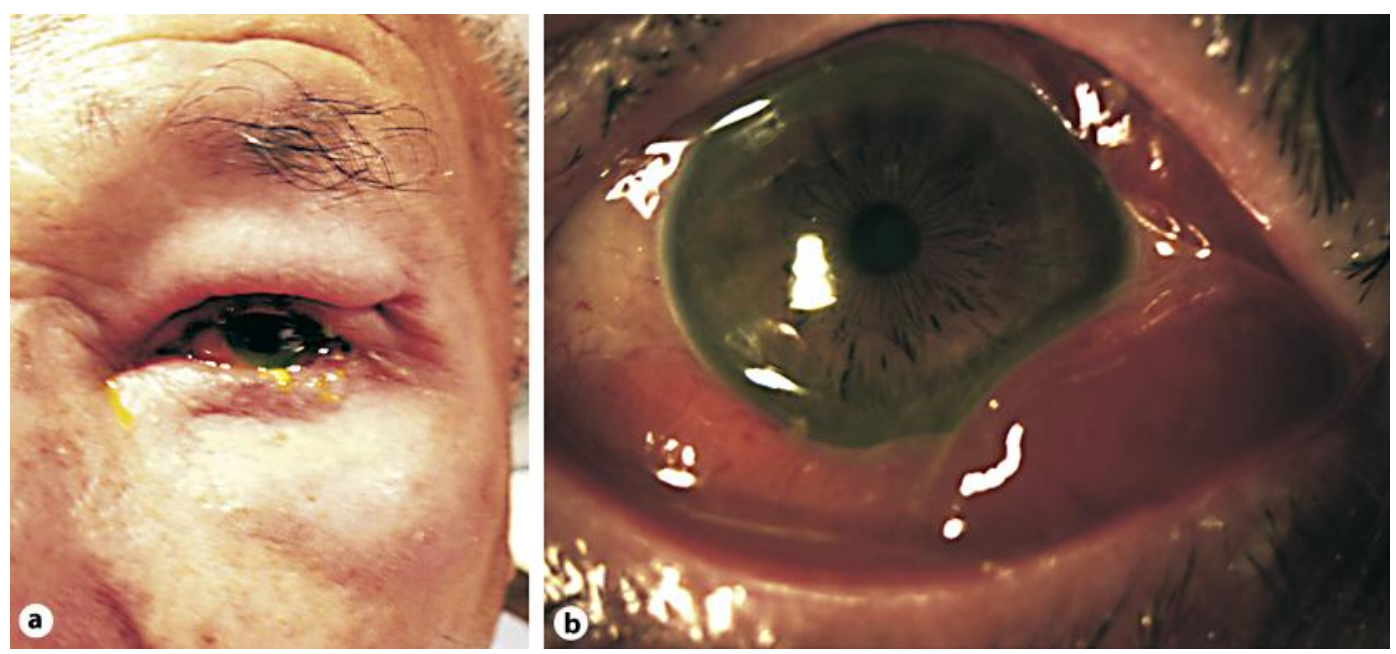

Fig. 2. Patient 6 hours after exposure to undiluted Ecballium elaterium fruit juice. a Periorbital edema. b Conjunctival edema is noted. 

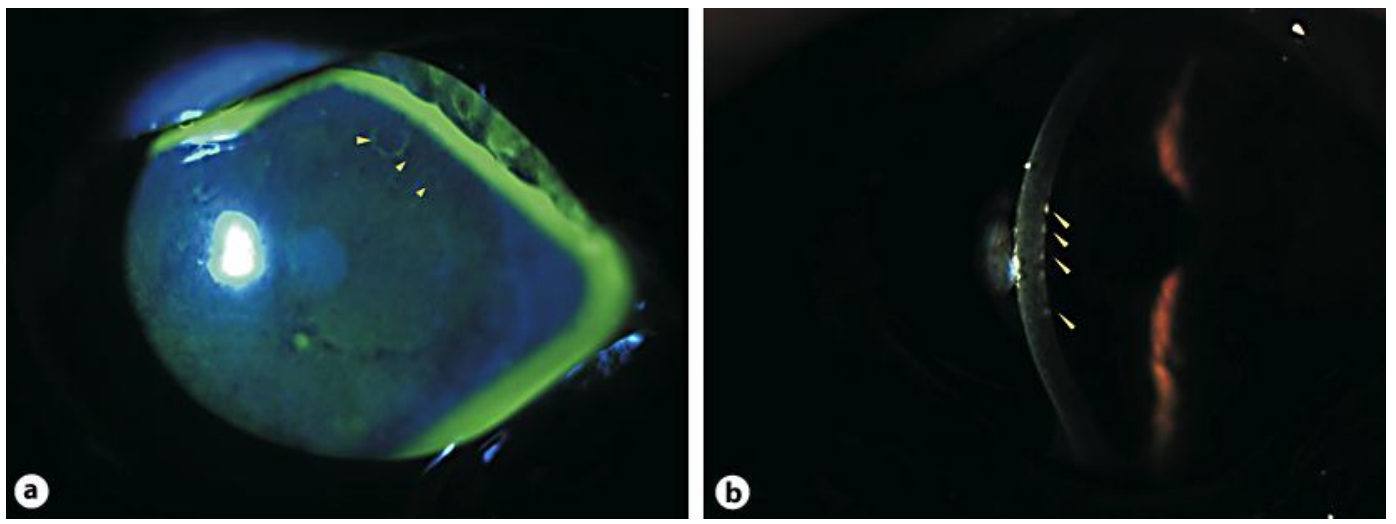

Fig. 3. a Well-defined edematous areas in the anterior peripheral upper quadrants of the cornea. b Descemet's membrane folds.

\section{References}

1 Raikhlin-Eisenkraft B, Bentur Y: Ecballium elaterium (squirting cucumber) - remedy or poison? J Toxicol Clin Toxicol 2000;38:305-308.

2 Sezik E, Yesilada E: Clinical effects of the fruit juice of the Ecballium elaterium in the treatment of sinusitis. J Toxicol Clin Toxicol 1995;33:381-383.

3 Sezik E, Yesilada E, Honda G, Takaishi Y, Takeda Y, Tanaka T: Traditional medicine in Turkey X. Folk medicine in Central Anatolia. J Ethnopharmacol 2001;75:95-115.

4 Sollmann T (ed): A Manual of Pharmacology and Its Applications to Therapeutics and Toxicology. Saunders Company, Philadelphia and London, 1917, p 176.

-5 Satar S, Gökel Y, Toprak N, Sebe A: Life-threatening uvular angioedema caused by Ecballium elaterium. Eur J Emerg Med 2001;8:337-339.

-6 Kloutsos G, Balatsouras DG, Kaberos AC, Kandiloros D, Ferekidis E, Economou C: Upper airway edema resulting from use of Ecballium elaterium. Laryngoscope 2001;111:1652-1655.

7 Vlachos P, Kanitsakis NN, Kokonas N: Fatal cardiac and renal failure due to Ecballium elaterium (squirting cucumber). J Toxicol Clin Toxicol 1994;32:737-738.

8 Kocak I, Karabela Y, Karaman M, Kaya F: Late onset diffuse lamellar keratitis as a result of the toxic effect of Ecballium elaterium herb. J Refract Surg 2006;22:826-827. 